\title{
Racecadotril in Management of Infant Diarrhea
}

\author{
Dr. Avinash Shankar \\ MD (Med), DCH, PhD Chairman, \\ National Institute of Health \& Research \\ Warisaliganj (Nawada), India \\ Dr. Shubham \\ MD (Pediatrics) \\ Vardaman Mahaveer Medical College \& Hospital, New Delhi \\ Dr. Farhat Jabeen \\ Project Officer, Centre for Diarrheal Disease \& Research \\ RA.Hospital \& Research Centre (Presently Medical Officer), \\ RBSK, Government of Bihar
}

\begin{abstract}
Acute diarrhea is considered $2^{\text {nd }}$ killer during infancy as commonly prescribed ant diarrheal agent ,constitute a composite of antimicrobial agent and anti protozoal drug, poses various drug induced untoward effects either due to super infection or drug adversity.

Interaction between diarrheal disease and nutritional status are complex and synergistic and serious issues globally., as they affect thousands of millions of young children every year and causes $>3$ millions death of children < 5yrs in spite of intensive filed based diagnosis and treatment.

Thus a planned study with therapeutically established molecule Racecadotril (Acetorphan), an enkephalinase inhibitor antisecretory and anti diarrheal used as safe and effective therapeutics for dioarrhea in adult and children is evaluated in infants in dose of $1.5 \mathrm{mg} / \mathrm{kg}$ at $8 \mathrm{hrly}$ dosefor its therapeutic effect and safety profile ${ }^{6}$ Infants taking Racecadotril as adjuvant orally ensures early change in consistency and frequency of lose motion without any drug adversity or disease's consequent squeal.
\end{abstract}

Keywords: diarrhea, acetorphan, mortality, antisecretory.

\section{INTRODUCTION}

Diarrhea ,a biggest infant killer worldwide specially in developing countries like India, Nepal, Bangladesh and Shrilanka, where a child suffers on an average 3-6 episodes of diarrhea in first year of life claiming death rate of 20-60/thousand children annually. Interaction between diarrheal disease and nutritional status are complex and synergistic and serious issues globally., as they affect thousands of millions of young children every year and causes $>3$ millions death of children $<5 y$ rs in spite of intensive filed based diagnosis and treatment ${ }^{1,2}$ usually 109 of every 1000 children dies before 5 yrs (Unicef report 2012) and 11\% death is due to diarrhea, present deth rate of 38 per thousand in India to be achieved by 2015 , though diarrheal death dropped in India Usually child loses water and electrolyte alike adult due to fairly large area of secreting intestinal mucosa ${ }^{7}$.

The commonest cause of during infancy is virus (Rotavirus) or non specific though diarrheas significantly alter nutrition but simultaneously malnutrition also predisposes diarrhea due to declined immune response and aggravated secretory function of intestinal mucosa.

As during infancy the major cause of diarrhea is increased secretion due to increased cyclic AMP during dentition phase or due to organismal toxin ${ }^{2}$. Inspite of its non bacterial pathogenesis, the commonly prescribed preparation constituting even contra indicated antimicrobial agent (Quinolone) combination is quite in vogue and prescribed by qualified and specialized clinician, which not only causes therapy related untoward effect but also presents with manifestation of super infection egcandidiasis, fungal diarrhea, urinary tract infectionand mucous colitis ${ }^{4}$. Though various anti diarrheal 
are in vogue (even containing contraindicated molecules), which not only cause various therapeutic hazards like post diarrhea mucous colitis, urinary tract infection, fungal super infection and mortality due to post diarrhea dehydration and encephalopathy?

Hence considering the mortality and morbidity in infants due to altered secretory and absorptive mechanism of intestinal mucosa, a clinical study to evaluate an anti secretory prodrug RACECADOTRIL in declining the secretion of intestinal mucosa and promotion of fluid and electrolyte transport in changing the consistency and frequency of stool and safety profile in infant diarrhea is planned

\section{MATERIALS AND METHODS}

\subsection{Design and Study}

Comparative clinical study to evaluate RACECADOTRIL orally in limiting fluid and electrolyte loss in infant diarrhea.

\subsection{Patients}

1760 infants presenting with lose motion with various stage of dehydration without any other systemic disease or sequelae attending at pediatric out door of RA.Hospital \& Research Centre during Jan 2008- March 2009 were selected by Centre for Diarrheal Disease Research (CDDR).

\subsection{Method}

After proper knowledge regarding the proposed study written consent of the parent was taken and selected infants were duly examined and patient's informants (parent or attendant) were interrogated thoroughly for frequency, consistency and odor of stool ,therapeutics taken and their effects and mode and type of feedings.

Patients were also assessed for their hydration and thermal state. Dehydration state was assessed as per following index of assessment.

\begin{tabular}{|l|l|}
\hline \multicolumn{1}{|c|}{ Dehydration } & \multicolumn{1}{|c|}{ Characteristic feature } \\
\hline Mild & Irritable, craving for water \\
\hline Moderate & $\begin{array}{l}\text { Irritable, weak pulse, restlessness, decreased urine volume , Depressed anterior } \\
\text { fontanel, Face dry and pinched }\end{array}$ \\
\hline Severe & $\begin{array}{l}\text { Moribund, apathetic, peripheral circulatory Failure, marked reduction in urine volume, } \\
\text { Eye ball markedly sunken, .lips parched, Face markedly dry and parched, buckle, } \\
\text { Mucosa dry, loss of skin turgor, craving for Water (intense thirst) }\end{array}$ \\
\hline
\end{tabular}

Selected patients were investigated for serum electrolyte, stool routine and culture, urine routine and culture was duly done.

Selected patients were classified into two groups constituting equal number of infants of similar status to adjudge the comparative therapeutic status of RACECADOTRIL in infant diarrhea.

\begin{tabular}{|l|l|}
\hline Group A & Anti diarrhea agent and Racecadotril \\
\hline Group B & Anti diarrhea agent \& ORS \\
\hline
\end{tabular}

Patients with severe dehydration irrespective of their therapeutic group were administered intravenous fluid in dose of $100 \mathrm{ml} / \mathrm{kg}$ in schedule of $-30 \mathrm{ml} / \mathrm{Kg}$ in first 30 minutes while rest $30 \mathrm{ml} / \mathrm{Kg}$ in next 1 hour and $40 \%$ in next 2 hours and index of hydration was adjudged by passage of urine.

In order to check or induce paralysis or neuritis in suspected cases of viral diarrhea as a precautionary measure intramuscular injections been duly avoided. Among the anti diarrheal recommended are Nitazoxnide dry syrup and Co -trimoxazole suspension in recommended therapeutic dose. Racecadotril powder was recommended in dose of $1.5 \mathrm{mg} / \mathrm{Kg}$ every 8 hours with palatable water/Oral Rehydration Solution. Irrespective of the nutritional status and infant feeding type, infant's mother were advised to feed their child on barley or rice water gruel for 72 hours to avoid a risk of lactose intolerance and milk or food induced intestinal cramps or agony.

Each mother or parent were given a follow up card to enter the following

- Frequency of lose motion every day 


\section{Racecadotril in Management of Infant Diarrhea}

- Consistency of stool i.e.

- watery, semisolid or formed

- Fever

- Excessive crying

- Abdominal distension,

- Status of dehydration,

- Urine out put

After completion of $72 \mathrm{hrs}$ of therapy, each patient were evaluated for consistency and frequency of stool, culture and sensitivity of stool and urine, blood for hematological status and renal statu Post therapy status of the patient was assessed as per following index i.e.

- any relapse,

- recurrence or persistence,

- urinary complaints,

- persistence of pyrexia,

- Mucous colitis.

Based on the therapeutic response and post therapy follow up, clinical response was graded as

\begin{tabular}{|l|l|}
\hline Clinical grades & \multicolumn{1}{c|}{ Characteristics } \\
\hline I & Completely formed stool within 48 hrs without any consequent sequel. \\
\hline II & $\begin{array}{l}\text { Decrease in frequency of stool and change in consistancy of stool in 48 hrs without any } \\
\text { adversity. }\end{array}$ \\
\hline III & Decline in frequency and consistency but no Formed stool with adversity \\
\hline IV & No effect within 72 hrs \\
\hline
\end{tabular}

\section{ObSERVATIONS}

Among the selected infants, majorities (39\%) were of age group 6-9 months and 17\% were of age group 3-6 months. 32\% infants had frequency of motion 4-6 every 24 hours while $19 \%$ shows $>13$ every 24 hours.( T-1)

Table1. Distribution of patients as per their age, sex and frequency of motion

\begin{tabular}{|l|l|l|l|l|l|l|l|l|}
\hline \multicolumn{1}{|c|}{ Age group } & \multicolumn{9}{c|}{ Number of patients } & \multicolumn{3}{c|}{$>13$} \\
\hline Frequency of motion/24hr & \multicolumn{2}{|c|}{$4-6$} & $7-9$ & \multicolumn{1}{c|}{12} & M & M & F \\
\hline & M & F & M & F & M & F & M \\
\hline 1-3 months & 50 & 46 & 56 & 40 & 32 & 20 & 42 & 30 \\
\hline 3-6 months & 60 & 48 & 46 & 35 & 30 & 22 & 32 & 25 \\
\hline 6-9 months & 120 & 89 & 110 & 78 & 94 & 68 & 76 & 45 \\
\hline 9-12months & 80 & 60 & 75 & 55 & 60 & 47 & 51 & 38 \\
\hline & 310 & 243 & 287 & 208 & 216 & 157 & 201 & 138 \\
\hline
\end{tabular}

Out of all $65 \%$ (1136) infants present with lose watery motion, $23 \%$ and $12 \%$ infants had greenish lose motion and lose motion with mucous and froth respectively, $85 \%$ had fever and $80 \%$ presented with scanty urine(T-2).

Table2. Distribution of patients as per clinical presentation

\begin{tabular}{|l|l|l|l|}
\hline \multicolumn{1}{|c|}{ Particulars } & \multicolumn{2}{c|}{ Number of patients } \\
\hline & \multicolumn{1}{|c|}{ Male } & \multicolumn{1}{c|}{ Total } \\
\hline Lose watery motion & 714 & 422 & 1136 \\
\hline Lose greenish motion & 190 & 213 & 403 \\
\hline Lose motion with froth & 110 & 111 & 221 \\
\hline Abdominal distension & 880 & 530 & 1410 \\
\hline Prone lying & 912 & 625 & 1537 \\
\hline Irritability & 1006 & 703 & 1709 \\
\hline Scanty urine & 718 & 698 & 1416 \\
\hline Depressed anterior fontanelle & 886 & 526 & 1412 \\
\hline Fever & 846 & 649 & 1495 \\
\hline
\end{tabular}


As per hydration status all are dehydrated but $41 \%$ and $39 \%$ were with severe and moderate dehydration respectively (T-3)

Table3. Distribution of patients as per their dehydration status

\begin{tabular}{|c|c|c|c|c|}
\hline Dehydration state & \multicolumn{4}{|c|}{ Number of patients } \\
\hline & Male & Female & Total & $\%$ \\
\hline Mild & 128 & 220 & 348 & 20 \\
\hline Moderate & 450 & 244 & 694 & 39 \\
\hline Severe & 436 & 282 & 718 & 41 \\
\hline
\end{tabular}

Stool examination of the infants shows absence of respective pathogens in 33\% male and 34\% female though $12 \%$ of both male and female Show presence of Shigella and $16 \%$ of male and $15 \%$ female shows presence of Salmonella, (T-4)

Table4. Distribution of patients as per status of stool pathogen

\begin{tabular}{|l|l|l|l|}
\hline \multicolumn{1}{|c|}{ Isolated pathogen } & \multicolumn{1}{c|}{ Number of patients } \\
\hline & \multicolumn{1}{|c|}{ Male } & \multicolumn{1}{c|}{ Total } \\
\hline No organism & 332 & 254 & 586 \\
\hline Salmonella & 160 & 109 & 269 \\
\hline Shigella & 124 & 088 & 212 \\
\hline Escheresia coli & 198 & 121 & 319 \\
\hline Giardia & 200 & 174 & 374 \\
\hline
\end{tabular}

No infants with history of fever show significant bacteriuria or positive Microstix -N test for Urinary tract infection. Hematological status of majority infants was within normal limit or non reveal hemoglobin deficiency or any haemato pathology.

All infants taking Rcecadotril shows earliest change in consistency and frequency of stool with complete normalization within 72 hours while others had deterioration of hydration status (39\%) and needed intravenous fluid administration with advocation of racecadotril.

Crave for water in infants on racecadotril ceased within 24 hours though some had within 12 hours while in others persisted for more than a week. 93\% infants taking racecadotril had grade I clinicopathological cure while others had worsening of hydration state in majority (89\%) and needed fluid transfusion and ad vocation of racecadotril.

\section{DISCUSSION}

In spite of enormous advancement in diarrheal management mortality and morbidity remain very common in infants due to acute diarrhea Present study reveals earliest decline in frequency and change in stool consistency, resulting in short duration of therapy and minimal loss of fluid and electrolytes, checks need of intravenous fluid and electrolyte supplementation.

Table5. Outcome of the study

\begin{tabular}{|l|c|c|c|c|}
\hline \multicolumn{1}{|c|}{ Particulars } & \multicolumn{3}{c|}{ Number of patients } \\
\hline & \multicolumn{2}{|c|}{ Group A } & \multicolumn{2}{c|}{ Group B } \\
\hline & $\begin{array}{c}\text { Male } \\
\mathbf{5 8 8}\end{array}$ & $\begin{array}{c}\text { Female } \\
(\mathbf{2 9 2})\end{array}$ & $\begin{array}{c}\text { Male } \\
(\mathbf{5 8 8})\end{array}$ & $\begin{array}{c}\text { Female } \\
(\mathbf{2 9 2})\end{array}$ \\
\hline Hydration status: & & & & \\
\hline Improved & in all & in all & 084 & 016 \\
\hline Declined & none & none & 504 & 276 \\
\hline Untoward sequel: & & & & \\
\hline Abdominal distension & none & none & 262 & 108 \\
\hline Vomiting & none & none & 280 & 128 \\
\hline Irritability & none & none & 314 & 192 \\
\hline Grade of clinical cure: & & & & \\
\hline I & 546 & 272 & 046 & 012 \\
\hline II & 042 & 020 & 488 & 072 \\
\hline III & - & - & 054 & 208 \\
\hline Post therapy sequel: & & - & & \\
\hline Mucous colitis & - & - & 117 & 144 \\
\hline UTI & - & - & 124 & 106 \\
\hline Persistent diarrhea & - & - & 044 & 173 \\
\hline
\end{tabular}


Not only this short duration of diseases check untoward effects as revealed by unaltered hematological, hepatic and renal function. Early change in consistency and decline in frequency of lose motion and loss of fluid and electrolytes in infants taking Racecadotril can be explained asRacecadotril, a pro drug which gets hydrolyzed to THIORPHAN and inhibits intestinal encaphalin ( a membrane bound metalo peptidase) and prolong the anti secretory effect of encaphalin resulting in reduced secretion of water and electrolyte in the intestinal lumen, ultimately declining the intestinal load and intestinal stretch receptor response, finally reduce stretch ,stimulation of the intestinal musculature leading to decline in tenesmus and defecation response.

Without increasing intestinal transit time and promoting bacterial colonization or fluid pooling in the distended bowel lumen or causing constipation

\section{CONCLUSION}

RACECADOTRIL, an anti secretory prodrug prolongs the anti secretory effect of encephalin decreases the intestinal over load ,promote water and electrolyte absorption and help change the consistency of stool, checks water and electrolyte loss and cut short both the duration and cost of therapy.

\section{ACKNOWLEDGEMENT}

We are thankful to Lyka Hetero for supply of adequate sample of Racecadotril sachet (ENUFF SACHET) for free distribution and parent of the patients who voluntarily accepted to join the study.

\section{REFERENCES}

[1] Grey, M; 430 Nutritional effect and management of diarrhea in infants Acta Pediatric supplement 1999, Aug,288(430)

[2] Cezand, JP et al; Treatment biomechanism of infectious acute diarrhea in infants and children. Archieves pediatrics, 2002; 9: 620-628

[3] Cojocaru, B; Bocquet, N; Timsit, S; Wille, C; Boursequet, C; and Marcobes, F etal; effect of Racecadotril in the management of acute diarrhea in infant and children. Arch. Pediatrics; 2002:9:774-779

[4] Salazer-lindo E etal; Racecadotril in treatment of acute watery diarrhea in children. New England journal of Medicine ,2000,343:463-467Teatment of diarrhealdisease, position, statement, Peduatric child health, Canadian Pediatric Society , 2003;8:455-458,463-468

[5] Alam, NH; Ashraf, H; Khan, WA, Kalam, MM; Fuens, GJ et al, Effect and tolerability of Racecadotril in treatment of cholera, Gut, 2003; 52: 1419-1423.

[6] Nagpal, Jitendra et al, Racecadotril in management of diarrhea in children, Indian pediatrics, 2004; 41: 1218-1224.

[7] Shankar, A; Recent advances in management of pediatric diarrhea, presented at update on diarrheal management ,International college of Pediatrics ,Toranto, September 91.

[8] Robert M. Issenman, Management of Diarrhea in Infants and Children, Can Fam Physician. 1987 May; 33: 1261-1264.

[9] DeWitt TG, Humphrey KF, McCarthy P. Clinical predictors of acute bacterial diarrhea in young children. Pediatrics. 1985 Oct; 76(4):551-556.

[10] Ram PK et al. (2008). Declines in case management of diarrhoea among children less than five years old. Bulletin of the World Health Organization, 86:161-240. 